\title{
Mood disorder and cancer onset: evidence from a population-based sample of Australian women
}

\author{
Stephanie P. Cowdery, ${ }^{1}$ (iD Amanda L. Stuart, ${ }^{1}$ (iD Julie A. Pasco, ${ }^{1,2,3}$ (iD Michael Berk, ${ }^{1,4,5,6}$ (iD \\ David Campbell, ${ }^{3}$ Ottar Bjerkeset, ${ }^{7}$ iD Lana J. Williams ${ }^{1}$ iD \\ ${ }^{1}$ Deakin University, Institute for Mental and Physical Health and Clinical Translation (IMPACT), School of Medicine, Barwon Health, Geelong, \\ Australia. ${ }^{2}$ Department of Medicine, Western Campus, University of Melbourne, St Albans, Australia. ${ }^{3}$ University Hospital Geelong, Barwon \\ Health, Geelong, Australia. ${ }^{4}$ Department of Psychiatry, University of Melbourne, Parkville, Australia. ${ }^{5}$ Florey Institute of Neuroscience and \\ Mental Health, Parkville, Australia. ${ }^{6}$ Orygen the National Centre of Excellence in Youth Mental Health, Parkville, Australia. ${ }^{7}$ Faculty of Nursing \\ and Health Sciences, Nord University, Norway.
}

\begin{abstract}
Objective: The role of mood disorders in cancer onset is unclear. The aim of this study was to investigate the association between mood disorder and incident cancer in a population-based sample of women.

Methods: Data were derived from women aged 28-94 years participating in the Geelong Osteoporosis Study. Mood disorder was identified via Clinical Interview (SCID-I/NP). Cancer data was obtained following linkage with the Victorian Cancer Registry. Demographic and lifestyle factors were selfreported. Nested case-control and retrospective study designs were utilized.

Results: In the case-control study $(n=807)$, mood disorder was documented for 18 of the $75(9.3 \%)$ cancer cases and among 288 controls $(24.0 \%$ vs. $39.3 \%, p=0.009)$. Prior exposure to mood disorder was associated with reduced cancer incidence (OR $0.49,95 \% \mathrm{Cl} 0.28-0.84)$; this was sustained following adjustment for confounders $\left(\mathrm{OR}_{\mathrm{adj}} 0.52,95 \% \mathrm{Cl} 0.30-0.90\right)$. In the retrospective cohort study $(n=655)$, among 154 women with a history of mood disorder at baseline, $13(8.5 \%)$ developed incident cancer during follow-up, whereas among 501 women with no history of mood disorder, $54(10.8 \%)$ developed incident cancer. Exposure to mood disorder was not associated with incident cancer over the follow-up period ( $\mathrm{HR} 0.58,95 \% \mathrm{Cl} 0.31-1.08, \mathrm{p}=0.09$ ).

Conclusion: Mood disorder was associated with reduced odds of cancer onset. However, this finding was not supported in the retrospective cohort study. Larger studies able to investigate specific cancers and mood disorders as well as underlying mechanisms in both men and women are warranted.
\end{abstract}

Keywords: Cancer incidence; mood disorder; cancer risk; women

\section{Introduction}

Mood disorders pose a substantial health and economic burden across the globe. ${ }^{1}$ Due to their chronic, often recurrent nature and common pathophysiological pathways, ${ }^{2,3}$ mood disorders have been associated with a host of physical conditions and illnesses, including cardiovascular disease, diabetes, gastroesophageal reflux disease, asthma, arthritis, and bone fracture. ${ }^{4-7}$ Moreover, mortality rates among those with mood disorders have been estimated to be $35 \%$ greater than in the general population, with the majority of these deaths due to comorbid chronic physical conditions. ${ }^{8}$

The association between psychological distress and poorer survival/increased mortality in populations with established cancer is well documented. ${ }^{9-15}$ The prevalence of elevated psychological distress among adult

Correspondence: Stephanie Cowdery, Deakin University, Institute for Mental and Physical Health and Clinical Translation (IMPACT), School of Medicine, Barwon Health, PO Box 281 (Barwon Health), Geelong, VIC, Australia, 3220.

E-mail: scowdery@deakin.edu.au

Submitted Feb 29 2020, accepted Jul 21 2020, Epub Sep 182020. patients with cancer is reported to be approximately $30-35 \%$ at the time of diagnosis and up to $45 \%$ upon disease recurrence. ${ }^{16,17}$ Thus, a diagnosis of cancer generates adjustment reactions with moderate to high levels of psychological distress that can, over time, develop into a depressive or anxiety disorder. ${ }^{18}$ The area of psychooncology goes beyond medical treatment to integrate psychological and social aspects of cancer. ${ }^{19}$ Established in the mid-1970s, this relatively new field covers many areas on the cancer continuum, including changing lifestyle habits to reduce risk of cancer onset, managing symptoms during active treatment and survivorship, and palliative and end-of-life care. ${ }^{19}$ Onset of mood and anxiety disorders after cancer diagnosis is well recognized within the health sector; its solidification is best exemplified by the inclusion of mandatory distress screening (i.e., the Distress Thermometer scale) for all

How to cite this article: Cowdery SP, Stuart AL, Pasco JA, Berk M, Campbell D, Bjerkeset $O$, et al. Mood disorder and cancer onset: evidence from a population-based sample of Australian women. Braz J Psychiatry. 2021;43:355-361. http://dx.doi.org/10.1590/1516-44462020-0932 
newly diagnosed cancer patients in Victoria, Australia. ${ }^{20}$ However, links between psychiatric disorders and cancer onset and risk are still largely unclear. ${ }^{19}$

Mood disorders are associated with immune and neuroendocrine dysregulation, as well as with behavioral changes, such as smoking, physical inactivity, and poor diet/excess calorie intake, which have been implicated in the etiology of many cancers. ${ }^{21,22}$ However, longitudinal studies assessing the association between mood disorder and cancer onset have not been conclusive, with some reporting positive associations, ${ }^{23-28}$ others reporting no association, ${ }^{29-33}$ and others still reporting negative associations. ${ }^{34-36}$ Possibly adding to the mixed findings, these studies have varied in population type and size, assessment of mood disorder, follow-up period, and cancer type.

Women are more likely than men to experience a mood disorder within their lifetime ${ }^{37,38}$ which may place them at increased risk for development of cancer due to the associated increase in lifestyle (smoking, sedentary behavior, poor diet) and non-lifestyle cancer risk factors compared to the general population. Thus, investigation of whether women with established mood disorders are indeed at increased risk of subsequent cancer development is warranted. Therefore, in this epidemiological study we aimed to investigate the association between mood disorder and cancer onset in a population-based cohort of Australian women spanning the adult age range.

\section{Methods}

\section{Participants}

Data from women participating in the Geelong Osteoporosis Study (GOS) were utilized. The GOS is a large population-based cohort study. Participants were randomly selected from electoral rolls for the Barwon Statistical Division (BSD) in south-eastern Australia. Between 1994 and 1997, 1494 women (aged 20-94 years) were recruited, with a participation of $77.1 \%$. These women have since returned for follow-up every 2-5 years. Further details have been published elsewhere. ${ }^{39}$ From a potential pool of 849 women who participated in the most recent female follow-up (2011-2014), those for whom psychiatric data were not available $(n=35)$ were excluded. This resulted in a sample of 814 women aged 28-94 years eligible for inclusion.

Two study designs were utilized, as described below.

\section{Nested case-control}

Adult-onset cancer cases and cancer-free controls were selected. For cases, exposures to a mood disorder prior to cancer onset were identified. One case was excluded due to having a childhood cancer and a further six excluded as they had self-reported cancer prior to 1982 . Thus, 807 women ( 75 cases and 732 controls) were included in the analyses. Exposure data for the cases pertained to the scheduled follow-up assessment which most closely preceded the date of cancer onset; for controls, the latest follow-up (2011-2014) data were used.

\section{Retrospective cohort study}

Over 20 years of data were available for 666 of the 814 women who underwent a structured psychiatric interview at the most recent assessment in 2011-2014. Those who had a diagnosis of cancer prior to baseline were excluded $(n=11)$, resulting in 655 eligible participants. Participants were then classified as having a history of mood disorder if they had experienced an episode prior to or at the time of their baseline appointment $(n=154)$; otherwise, they were classified as free of a mood disorder $(n=501)$. These participants were followed until the onset of cancer, death, or until the end of the study in 2014. Exposure data for the participants was taken from the baseline assessment (1993-1997).

\section{Data}

\section{Cancer}

Cancer onset was determined following data linkage with the Victorian Cancer Registry (VCR). Cancer reporting to the registry by hospitals, pathology centers, and screening registers and centers is mandated by law. The VCR records all invasive cancers, in-situ carcinomas, benign tumors, and tumors of uncertain behavior. Nonmelanoma basal and squamous cell skin carcinomas (BCC and SCC respectively) are not recorded. For every cancer case, a minimum amount of information is collected, including patient demographics such as name, date of birth, and residential address, as well as tumor-specific details including (but not limited to) date of diagnosis, site, type, and overall grade. ${ }^{40}$ All malignant neoplasms with ICD-10 codes ranging from C000.0-C96 were included in the analyses.

Information on self-reported cancer was obtained via GOS questionnaires. Participants were required to tick yes if they had ever had the following cancer(s): lung, bowel, breast, uterus, cervix, throat, brain tumor, melanoma, nonmelanoma skin cancer (BCC or SCC), leukemia, myeloma or other (asked to specify type); and indicate their age at onset (years). As the VCR established mandatory reporting from 1982, all participants in the analyses were cross-checked for a self-reported cancer occurring prior to this date.

\section{Mood disorder}

The Structured Clinical Interview for Diagnostic and Statistical Manual of Mental Disorders, Fourth Edition, Non-patient edition (SCID-I/NP), is a validated semistructured clinical interview to assess DSM-IV Axis I disorders. ${ }^{41}$ This tool enables identification of major depressive disorder, dysthymic disorder, minor depressive disorder, bipolar disorder (I, II, or other), mood disorder due to a general medical condition and/or substance induced mood disorders, and depressive disorder not otherwise specified, as well as the age of onset. In the present study, classification as having a lifetime history of mood disorder was contingent on meeting past and/or current diagnostic criteria for any mood disorder. The SCID-I/NP was administered at the most recent follow-up 
(2011-2014) by trained clinical researchers who had a minimum postgraduate qualification in psychology and had completed subsequent training including live interviews under supervision. ${ }^{42}$

\section{Other data}

Demographic, clinical, and lifestyle data were self-reported at baseline and follow-up appointments. Education (highest level completed) was self-reported and grouped as (i) primary/part secondary, (ii) completed secondary, and (iii) post-secondary (university/other). Height was measured using a wall-mounted stadiometer to the nearest $0.1 \mathrm{~cm}$ and weight was recorded to the nearest $0.1 \mathrm{~kg}$ using an electronic scale. Body mass index (BMI) was calculated as $\mathrm{kg} / \mathrm{m}^{2}$. Current tobacco smoking status (manufactured or hand-rolled cigarette, cigar, or pipe) was self-reported and dichotomized into current smoker versus non-smoker. Habitual physical activity was measured on a 7-point scale ranging from very active to bedfast ${ }^{39}$ and classified as active if mobility was identified as very active or active; otherwise, participants were classified as sedentary. The number of standard drinks per week was documented and converted to grams per day $(\mathrm{g} / \mathrm{d})$, based on the assumption that one standard drink is equivalent to $10 \mathrm{~g}$ of alcohol. Mortality was obtained via data linkage with the Australian National Deaths Index (ANDI).

\section{Statistical analyses}

Statistical analyses were performed using Minitab version 16 and SPSS for Windows version 22. Differences in characteristics between groups were determined using $t$ tests for continuous parametric variables, the KruskalWallis test for nonparametric continuous variables and for discrete variables, and chi-square tests or Fisher's exact test when expected cell counts were less than five.

In the nested case-control study, logistic regression was used to calculate odds ratios (OR) with 95\% confidence intervals $(95 \% \mathrm{Cls})$ to determine the association between mood disorder and cancer. Potential covariates including age, education, BMI, smoking status, alcohol consumption, and physical activity level were tested sequentially and retained if significant. In the retrospective cohort study, the relationship between mood disorder and de-novo cancer onset was examined using Cox proportional hazards models to calculate hazards ratios (HR) with $95 \% \mathrm{Cls}$. A p-value $<0.05$ was considered significant.

\section{Ethics statement}

The GOS was approved by the human research ethics committees of Barwon Health (project 92/01) and Deakin University (project 2013-116). Written informed consent was obtained from all participants.

\section{Results}

\section{Nested case-control study}

There were 75 women with a confirmed diagnosis of cancer: one (1.3\%) respiratory, two (2.7\%) lip/oral cavity/ pharynx, four $(5.3 \%)$ thyroid, seven (9.3\%) lymphoid/ hematopoietic, nine (12\%) melanoma/other neoplasms of skin, nine (12\%) female genital organs, 20 (26.7\%) digestive organs, and $23(30.7 \%)$ breast. Characteristics of the women with and without cancer are shown in Table 1. Those with cancer were older, less likely to be physically active, and less likely to have completed secondary or postsecondary education; otherwise, no further differences were detected between the groups. A prior history of mood disorder was documented for 18 of the 75 cancer cases and 288 of 732 controls (24.0\% vs. $39.3 \%$, $p=0.009)$. Mood disorder was associated with a reduced odds of cancer (OR 0.49, 95\%Cl 0.28-0.84, $p=0.007$ ). After adjustment for education, the relationship between mood disorder and cancer onset was sustained $\left(\mathrm{OR}_{\mathrm{adj}} 0.52,95 \%\right.$ $\mathrm{Cl} 0.30-0.90, \mathrm{p}=0.016)$. Further adjustments for age, $\mathrm{BMI}$, current smoking, physical activity level, and alcohol consumption did not contribute to the final model.

\section{Retrospective cohort study}

Women $(n=655)$ were followed from baseline over a period of 9,798 person-years ( $p$-yr). Those with a history of mood disorder had a longer follow-up time in years compared to those with no history of mood disorder; otherwise, the groups were similar regarding education,

Table 1 Participant characteristics in the nested case-control study $(n=807)$

\begin{tabular}{|c|c|c|c|}
\hline & Cancer cases $n=75$ & Controls $n=732$ & $p$-value \\
\hline Mood disorder (prior to cancer) & $18(24.0)$ & $288(39.3)$ & 0.009 \\
\hline Age (years) & $61.8(51.7-71.7)$ & $54.7(41.1-68.0)$ & 0.004 \\
\hline $\mathrm{BMI}\left(\mathrm{kg} / \mathrm{m}^{2}\right)$ & $27.3(24.3-32.6)$ & $27.1(23.7-31.9)$ & 0.454 \\
\hline Smoking (current) & $4(5.3)$ & $86(11.8)$ & 0.093 \\
\hline Physically active & 9 (12.2) & $176(24.7)$ & 0.016 \\
\hline Alcohol $(g / d)$ & $1.43(0.0-8.5)$ & $2.9(0.0-8.6)$ & 0.168 \\
\hline Education (highest level completed) & & & $<0.001$ \\
\hline Primary/part secondary & $46(62.2)$ & $286(39.7)$ & \\
\hline Completed secondary & $11(14.9)$ & $116(16.1)$ & \\
\hline Postsecondary (university/other) & $17(23.0)$ & $318(44.2)$ & \\
\hline
\end{tabular}

Data presented as median (interquartile range) or $n(\%)$.

$\mathrm{BMI}=$ body mass index. 
Table 2 Participant characteristics in the retrospective cohort study $(n=655)$

\begin{tabular}{|c|c|c|c|}
\hline & Mood disorder (prior to baseline) $n=154$ & No mood disorder $n=501$ & p-value \\
\hline Age (years) & $43.6(34.9-52.7)$ & $44.0(33.4-56.2)$ & 0.630 \\
\hline Follow-up (years) & $16.5(15.8-17.1)$ & $16.0(14.5-16.8)$ & $<0.001$ \\
\hline BMI $\left(\mathrm{kg} / \mathrm{m}^{2}\right)$ & $25.9(22.6-29.4)$ & $25.3(22.5-29.5)$ & 0.383 \\
\hline Smoking (current) & $30(19.5)$ & $66(13.2)$ & 0.053 \\
\hline Physically active & $20(13.0)$ & 78 (15.6) & 0.432 \\
\hline Alcohol $(g / d)$ & $2.9(0.0-7.3)$ & $2.9(0.0-7.1)$ & 0.364 \\
\hline Education & & & 0.202 \\
\hline Primary/part secondary & $77(50.0)$ & $267(53.3)$ & \\
\hline Completed secondary & $32(20.8)$ & $122(24.4)$ & \\
\hline Postsecondary (university/other) & $45(29.2)$ & $112(22.4)$ & \\
\hline
\end{tabular}

Data presented as median (interquartile range) or $\mathrm{n}(\%)$.

$\mathrm{BMI}=$ body mass index.

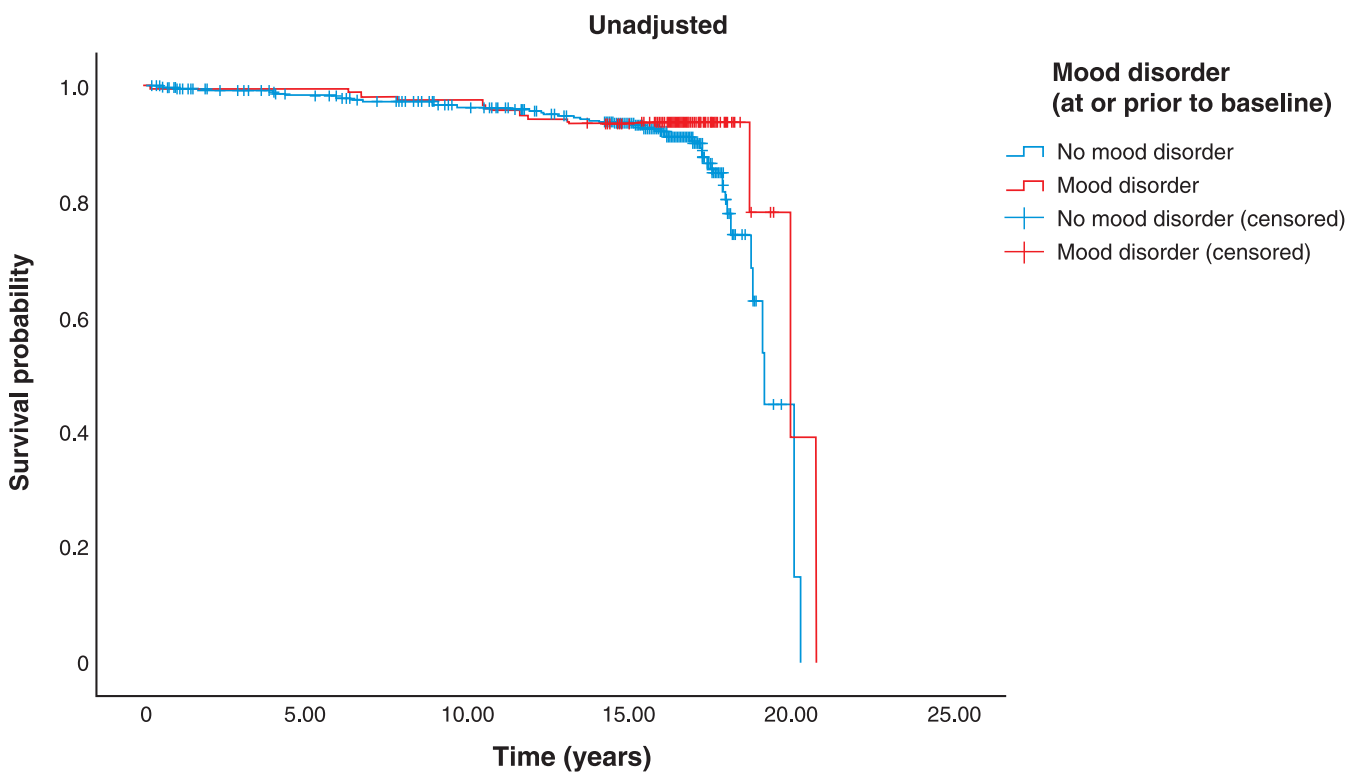

Figure 1 Kaplan-Meier survival curve showing cancer-free time over the 20-year period for women exposed and unexposed to mood disorder at baseline.

age, BMI, smoking status, physical activity level, and alcohol consumption at baseline (Table 2). During the study period, there were $67(10.2 \%)$ incident cancers and $34(5.2 \%)$ deaths. Among 154 women with a history of mood disorder at baseline, 13 (8.5\%) developed incident cancer during follow-up, whereas among 501 women with no history of mood disorder, 54 (10.8\%) developed incident cancer. Exposure to mood disorder was not associated with incident cancer over the follow-up period (HR 0.58, 95\% $0.31-1.08, \mathrm{p}=0.09$; Figure 1).

\section{Discussion}

Results from the nested case-control portion of this study indicated that mood disorder is associated with a reduction in the likelihood of cancer onset, independent of education, age, BMI, smoking, physical activity level, and alcohol consumption. However, no significant association between lifetime history of mood disorder and incident cancer was observed in the retrospective cohort study.
Consistent with a recent finding investigating the association between mood disorders and a host of subsequent medical conditions, Momen et al. ${ }^{43}$ followed 5.9 million members of the Danish population from 2000 to 2016 and assessed a wide range of mental disorders and medical conditions, including cancer. Following adjustment for age, sex, and calendar time, mental disorders were almost universally associated with an increased risk of each of the included medical conditions; however, the inverse was observed between mental conditions and cancer (HR 0.82; $95 \% \mathrm{Cl}$ 0.80-0.84). Similarly, a longitudinal prospective study by Chang et al. ${ }^{44}$ investigated over 600,000 adults (aged 30-64 years) from the Korean population. Over the 19-year study period, depressive symptomology (measured via a questionnaire based on DSM-IV criteria) was associated with a reduced incidence of overall cancer among women (HR 0.90, 95\% $\mathrm{Cl}$ 0.83-0.98). Furthermore, an inverse association between mood disorder and de-novo cancer onset has been reported in studies investigating site-specific cancers, with a reduced risk of cancer noted among breast ${ }^{45}$ and cervical ${ }^{32}$ sites in women. In 
addition, reductions in cancer onset have been noted in prostate (men) and rectal (men and women) cancer sites. ${ }^{32,46}$ Bipolar disorder has also been shown to be associated with a reduced risk of cancer. In another nationwide, population-based, longitudinal study with over 1.7 million participants in Denmark, those with a diagnosis of mania or bipolar disorder had an approximately $40 \%$ reduced rate of renal or upper urinary tract tumors, which was sustained after adjustment for age, sex, employment status, psychotropic and other medication use. ${ }^{34}$ Antipsychotic (but not lithium), anticonvulsant, and antidepressant treatment was also associated with a reduction, albeit small, in the incidence rate of renal or other upper urinary tract tumors. ${ }^{34}$ These findings are further supported by the findings of Huang et al., ${ }^{36}$ who reported that bipolar patients taking lithium had a reduced overall risk of cancer onset.

There are several potential mechanisms which may account for an inverse association between mood disorder and cancer. Mood disorders are characterized by increased levels of pro-inflammatory cytokines, ${ }^{47-51}$ possibly as a result of immune-system adaptation to multiple stressors associated with psychiatric disorders, including but not limited to smoking, physical inactivity, and poor diet. $^{52}$ Homeostatic adaptation to exogenous threats by upregulation may come at the cost of increased vulnerability to inflammation and related tissue damage, ${ }^{53}$ which has been associated with immune dysregulation and development of certain cancers. ${ }^{54-57}$ However, increased immune activation and surveillance has also been hypothesized to reduce cancer risk via prevention or resolution of infection by viruses associated with cancer development. ${ }^{58}$ In addition, expression of immune mediators, combined with activation of select cells and factors within the tumor microenvironment, may also influence whether inflammation promotes tumor growth or antitumor host immunity. ${ }^{59,60}$ Biological and inflammatory mechanisms were not explored in this study. As such, whether inflammation and associated immune profiles mediate any association(s), positive or negative, between mood disorder and incident cancer remains to be confirmed. Larger population-based studies are required.

Those with a mood disorder can experience sedentary behaviour and social isolation. ${ }^{61}$ In turn, these individuals may be less likely to present to health care professionals, which may impact the likelihood of receiving a prompt cancer diagnosis. In addition, the somatic symptoms of depression can overlap with those of cancer, including sleep disturbances, fatigue, and loss of appetite. As such, there is the possibility that symptoms of early-stage cancers may be similarly ascribed to, and potentially interpreted as, depressive symptomology, although it is likely that as cancer progresses and is fully expressed, detection will occur. ${ }^{62-64}$ This may reflect why some other studies have found an increased risk of cancer among individuals with depressive symptomology, especially within the first year of diagnosis. On the other hand, potential misclassification may result in a survival bias. Investigating stage at diagnosis for those with and without a history of depression may further clarify this explanation. In addition, findings may have clinical implications and contribute to understanding the decreased survival observed in cancer patients with depression compared to those patients without. ${ }^{65,66}$

Mood disorder is associated with increased morbidity and a reduced life expectancy compared to the general population. As such, the negative association may reflect premature mortality from other medical conditions in the mood disorder group, such as cardiovascular conditions and stroke. ${ }^{67-75}$ Although in the present study women with a history of mood disorder at baseline had a slightly longer follow-up time compared to those with no history of mood disorder, further analyses highlighted no significant differences in deaths recorded during the followup period for women with a history of mood disorder at baseline compared to those with no such history $(p=0.411)$.

Strengths of the current study include the comprehensive and longitudinal nature of the data, allowing for temporal investigation, and that participants were selected at random from the electoral roll rather than by disease status. Likewise, use of a structured clinical interview the gold-standard validated tool for assessing psychopathology - provided information on current and lifetime history of mood disorder as well as age of onset, rather than just psychiatric symptomology. Furthermore, data on cancer diagnoses were obtained objectively from a comprehensive cancer registry. The VCR was initiated in 1982 and is the most comprehensive and reliable cancer registry in the state of Victoria due to mandatory reporting laws; thus, it is unlikely that any cancer diagnoses have been overlooked in this study. As with all observational studies, results could be biased by unrecognized or residual confounding factors, and may not be generalizable to other populations of women, men, or certain cancer subtypes. Furthermore, as case numbers were relatively low in the retrospective cohort study, the study may have been underpowered to detect an association. Moreover, power constraints prevented specific subtype analyses and exploration of mood disorder specifiers, such as specific mood disorders, chronicity, and whether individuals were medicated. Therefore, heterogeneous biological mechanisms may be at play.

In conclusion, this study adds to the evidence base exploring the association between mood disorder and risk of incident cancer in women. While a negative association was observed in the nested case-control study, this finding was not supported in the retrospective cohort study. As such, larger studies able to investigate specific cancers and mood disorders as well as underlying mechanisms, in both men and women, are warranted.

\section{Acknowledgements}

The Geelong Osteoporosis Study (GOS) has received funding from the Victorian Health Promotion Foundation (ID 91-0095) and the National Health and Medical Research Council (NHMRC; ID 251638, ID 299831, ID 628582) of Australia. The funding organizations played no role in the design or conduct of the study, in the collection, management, analysis, and interpretation of the data, nor in the preparation, review, and approval of the manuscript. 
SPC is supported by a PhD stipend from IMPACT SRC at Deakin University. MB is supported by NHMRC Senior Principal Research Fellowships (APP1059660 and APP 1156072). LJW is supported by a NHMRC Career Development Fellowship (1064272) and a NHMRC Investigator grant (1174060).

We would like to acknowledge the women who participated in the GOS, the Victorian Cancer Registry (VCR) for cancer data, and the Australian Institute for Health and Welfare (AlHW) for deaths data.

\section{Disclosure}

\section{The authors report no conflicts of interest.}

\section{References}

1 World Health Organization (WHO). The global burden of disease: 2004 update. Geneve: WHO; 2004.

2 Andrews G. Should depression be managed as a chronic disease? BMJ. 2001;322:419-21.

3 McIntyre RS, Rasgon NL, Kemp DE, Nguyen HT, Law CW, Taylor VH, et al. Metabolic syndrome and major depressive disorder: co-occurrence and pathophysiologic overlap. Curr Diab Rep. 2009;9:51-9.

4 Farmer A, Korszun A, Owen MJ, Craddock N, Jones L, Jones I, et al. Medical disorders in people with recurrent depression. $\mathrm{Br} \mathrm{J}$ Psychiatry. 2008;192:351-5.

5 Sanna L, Stuart AL, Pasco JA, Kotowicz MA, Berk M, Girardi P, et al. Physical comorbidities in men with mood and anxiety disorders: a population-based study. BMC Med. 2013;11:110.

6 Kesler RC, Angermeyer M, Anthony JC, De Graaf R, Demyttenaere $\mathrm{K}$, Gasquet I, et al. Lifetime prevalece and age-of-onset ditributions of mental disorders in the World Health Organizations World Mental Health Survey Initiative. World Psychiatry. 2007;6:168-76.

7 Moussavi S, Chatterji S, Verdes E, Tandon A, Patel V, Ustun B. Depression, chronic diseases, and decrements in health: results from the World Health Surveys. Lancet. 2007;370:851-8.

8 World Health Organization (WHO). Premature death among people with severe mental disorders [Internet]. 2018 [cited 2020 Aug 5]. https://www.who.int/mental health/management/info sheet.pdf

9 Chan CM, Ahmad WA, Yusof MM, Ho GF, Krupat E. Effects of depression and anxiety on mortality in a mixed cancer group: a longitudinal approach using standardised diagnostic interviews. Psychooncology. 2015;24:718-25.

10 Kisely S, Crowe E, Lawrence D. Cancer-related mortality in people with mental illness. JAMA Psychiatry. 2013;70:209-17.

11 Mols F, Husson O, Roukema JA, van de Poll-Franse LV. Depressive symptoms are a risk factor for all-cause mortality: Results from a prospective prpulatioon-based study among 3,080 cancer survivors from the PROFILES registry. J Cancer Surviors. 2013;7:484-92.

12 Perini G, Grigoletti L, Hanife B, Biggeri A, Tansella M, Amaddeo F. Cancer mortality among psychiatric patients treated in a communitybased system of care: a 25-year case register study. Soc Psychiatry Psychiatr Epidemiol. 2014;49:693-701.

13 Wikman A, Ljung R, Johar A, Hellstadius Y, Lagergren J, Largergren P. Psychiatric morbidity and survival after surgery for esophageal cancer: a population-based cohort study. J Clin Oncol. 2015;33: 448-54.

14 Batty GD, Whitley E, Gale CR, Osborn D, Tynelius P, Rasmussen F. Impact of mental health problems on case fatality in male cancer patients. Br J Cancer. 2012;106:1842-5.

15 Chang CK, Hayes RD, Broadbent MT, Hotopf M, Davies E, Moller H, et al. A cohort study on mental disorders, stage of cancer at diagnosis and subsequent survival. BMJ Open. 2014;4:ee004295.

16 Zabora J, BrintzenhofeSzoc K, Curbow B, Hooker C, Piantadosi S. The prevalence of psychological distress by cancer site. Psychooncology. 2001;10:19-28.

17 Burgess C, Cornelius V, Love S, Graham J, Richards M, Ramirez A. Depression and anxiety in women with early breast cancer: five year observational cohort study. BMJ. 2005;330:702.
18 Victoria State Govenment. Victorian population health survey 20112012 [Internet]. [cited 2020 Aug 10]. www2.health.vic.gov.au/publichealth/population-health-systems/health-status-of-victorians/surveydata-and-reports/victorian-population-health-survey/victorian-popula tion-health-survey-2011-12

19 Holland JC. History of psycho-oncology: overcoming attitudinal and conceptual barriers. Psychosom Med. 2002;64:206-21.

20 National Comprehensive Cancer Network. Distress management. Clinical practice guidelines. J Natl Compr Canc Netw. 2003;1:344-74.

21 Berk M, Williams LJ, Jacka FN, O’Neil A, Pasco JA, Moylan S, et al. So depression is an inflammatory disease, but where does the inflammation come from? BMC Med. 2013;11:200.

22 Bortolato B, Hyphantis TN, Valpione S, Perini G, Maes M, Morris G, et al. Depression in cancer: Tte many biobehavioral pathways driving tumor progression. Cancer Treat Rev. 2017;52:58-70.

23 Penninx BW, Guralnik JM, Pahor M, Ferrucci L, Cerhan JR, Wallace $\mathrm{RB}$, et al. Chronically depressed mood and cancer risk in older persons. J Natl Cancer Inst. 1998;90:1888-93.

24 Gross AL, Gallo JJ, Eaton WW. Depression and cancer risk: 24 years of follow-up of the Baltimore Epidemiologic Catchment Area sample. Cancer Causes Control. 2010;21:191-9.

25 Kroenke C, Bennett GG, Fuchs C, Giovannucci E, Kawachi I, Schernhammer E, et al. Depressive symptoms and prospective incidence of colorectal cancer in women. Am J Epidemiol. 2005; 162:839-48.

26 McGee R, Williams S, Elwood M. Depression and the development of cancer: a meta-analysis. Soc Sci Med. 1994;38:187-92.

27 Huang T, Poole EM, Okereke OI, Kubzansky LD, Eliassen AH, Sood AK, et al. Depression and risk of epithelial ovarian cancer: results from two large prospective cohort studies. Gynecol Oncol. 2015;139:481-6.

28 Jia Y, Li F, Zhao JP, Leng MM, Chen L. Depression and cancer risk: a systematic review and meta-analysis. Public Health. 2017;149:138-48.

29 Kaplan GA, Reynolds P. Depression and cancer mortality and morbidity: prospective evidence from the Alameda County study. J Behav Med. 1988;11:1-13.

30 Hahn RC, Petitti DB. Minnesota multiphasic personality inventoryrated depression and the incidence of breast-cancer. Cancer. 1988; $61: 845-8$

31 Zonderman AB, Costa PT Jr, Mccrae RR. Depression as a risk for cancer morbidity and mortality in a nationally representative sample. JAMA. 1989;262:1191-5.

32 Dalton SO, Mellemkjaer L, Olsen JH, Mortensen PB, Johansen C. Depression and cancer risk: a register-based study of patients hospitalized with affective disorders, Denmark, 1969-1993. Am J Epidemiol. 2002;155:1088-95.

33 Niles A, O'Donovan A. Comparing anxiety and depression to obesity and smoking as predictors of major medical illnesses and somatic symptoms. Health Psychol. 2019;38:172-81.

34 Kessing LV, Gerds TA, Feldt-Rasmussen B, Andersen PK, Licht RW. Lithium and renal and upper urinary tract tumors - results from a nationwide population-based study. Bipolar Disord. 2015;17:805-13.

35 Martinsson L, Westman J, Hallgren J, Osby U, Backlund L. Lithium treatment and cancer incidence in bipolar disorder. Bipolar Disord. 2016;18:33-40.

36 Huang R, Hsieh KP, Huang WW, Yang YH. Use of lithium and cancer risk in patients with bipolar disorder: population-based cohort study. Br J Psychiatry. 2016;209:393-9.

37 Department of Health and Ageing. National mental health report 2013: tracking progress of mental health reform in Australia 19932011 [Internet]. 2013 [cited 2020 Aug 11]. www1.health.gov.au/internet/main/publishing.nsf/content/B090F03865A7FAB9CA257C1B0079 E198/\$File/rep13.pdf

38 Australian Bureau of Statisctics. National survey of mental health and Wellbeing: summary of results, 2007 [Internet]. 2008 [cited 2020 Aug 11]. www.abs.gov.au/AUSSTATS/abs@.nsf/Lookup/4326.0Main + Features32007?OpenDocument

39 Pasco JA, Nicholson GC, Kotowicz MA. Cohort profile: Geelong osteoporosis study. Int J Epidemiol. 2012;41:1565-75.

40 Cancer Council Victoria. Victorian cancer registry2014 [cited 2019]. www.cancervic.org.au/research/registry-statistics/vcr

41 First M, Spizer R, Gibbon M, Williams J. Structured clinical interview for DSM-IV-TR Axis I disorders, research version, non-patient edition. (SCID-I/NP) New York: Biometrics Research New York State Psychiatric Institute; 2002. 
42 Williams L, Jacka F, Pasco J, Henry M, Dodd S, Nicholson G, et al. The prevalence of mood and anxiety disorders in Australian women. Australas Psychiatry. 2010;18:250-5.

43 Momen NC, Plana-Ripoll O, Agerbo E, Benros ME, Borglum AD, Christensen MK, et al. Association between mental disorders and subsequent medical conditions. N Engl J Med. 2020;382:1721-31.

44 Chang HY, Keyes KM, Mok Y, Jung KJ, Shin YJ, Jee SH. Depression as a risk factor for overall and hormone-related cancer: the Korean cancer prevention study. J Affect Disord. 2015;173:1-8.

45 Nyklícek I, Louwman WJ, Van Nierop PW, Wijnands CJ, Coebergh JW, Pop VJ. Depression and the lower risk for breast cancer development in middle-aged women: a prospective study. Psychol Med. 2003;33:1111-7.

46 Lemogne C, Consoli SM, Melchior M, Nabi H, Coeuret-Pellicer M, Limosin F, et al. Depression and the risk of cancer: a 15-year followup study of the GAZEL cohort. Am J Epidemiol. 2013;178:1712-20.

47 Dowlati Y, Herrmann N, Swardfager W, Liu H, Sham L, Reim EK, et al. A meta-analysis of cytokines in major depression. Biol Psychiatry. 2010;67:446-57

48 Liu Y, Al-Sayegh H, Jabrah R, Wang W, Yan F, Zhang J. Association between $C$-reactive protein and depression: modulated by gender and mediated by body weight. Psychiatry Res. 2014;219:103-8.

49 Valkanova V, Ebmeier KP, Allan CL. CRP, IL-6 and depression: a systematic review and meta-analysis of longitudinal studies. J Affect Disord. 2013;150:736-44.

50 Kohler O, Benros ME, Nordentoft M, Farkouh ME, lyengar RL, Mors $O$, et al. Effect of anti-inflammatory treatment on depression, depressive symptoms, and adverse effects: a systematic review and meta-analysis of randomized clinical trials. JAMA Psychiatry. 2014; 71:1381-91.

51 Raison C, Rutherford RE, Woolwine BJ, Shuo C, Schettler P, Drake $\mathrm{DF}$, et al. A randomized controlled trial of the tumor necrosis factor antagonist infliximab for treatment-resistant depression: the role of baseline inflammatory biomarkers. JAMA Psychiatry. 2013; 70:31-41.

52 Schiepers OJ, Wichers MC, Maes M. Cytokines and major depression. Prog Neuropsychopharmacol Biol Psychiatry. 2005;29:201-17.

53 Tang Z, Sheng $H$, Zheng X, Ying L, Wu L, Liu D, et al. Upregulation of circulating cytokeratin 20 , urokinase plasminogen activator and C-reactive protein is associated with poor prognosis in gastric cancer. Mol Clin Oncol. 2015;3:1213-20.

54 Woo HD, Kim K, Kim J. Association between preoperative C-reactive protein level and colorectal cancer survival: a meta-analysis. Cancer Causes Control. 2015;26:1661-70.

55 Shrotriya S, Walsh D, Bennani-Baiti N, Thomas S, Lorton C. $\mathrm{C}$-reactive protein is an important biomarker for prognosis tumor recurrence and treatment response in adult solid tumors: a systematic review. PLoS One. 2015;10:e0143080.

56 Shi T, Ma Y, Yu L, Jiang J, Shen S, Hou Y, et al. Cancer immunotherapy: a focus on the regulation of immune checkpoints. Int $\mathrm{J}$ Mol Sci. 2018;19:1389.

57 Blume J, Douglas SD, Evans DL. Immune suppression and immune activation in depression. Brain Behav Immun. 2011;25:221-9.

58 Heber D, Blackburn G, Go V, Milner J. Nutritional oncology. 2nd ed. Netherlands: Elsevier; 2006.
59 Chow MT, Moller A, Smyth MJ. Inflammation and immune surveillance in cancer. Semin Cancer Biol. 2012;22:23-32.

60 Grivennikov SI, Greten FR, Karin M. Immunity, inflammation, and cancer. Cell. 2010;140:883-99.

61 Vancampfort D, Hallgren M, Schuch F, Stubbs B, Smith L, Rosenbaum $\mathrm{S}$, et al. Sedentary behavior and depression among community-dwelling adults aged $\geqslant 50$ years: results from the irish longitudinal study on ageing. J Affect Disord. 2020;262:389-96.

62 Nikendei C, Terhoeven V, Ehrenthal JC, Maatouk I, Wild B, Herzog W, et al. Depression profile in cancer patients and patients without a chronic somatic disease. Psychooncology. 2018;27:83-90.

63 Die Trill M. Psychological aspects of depression in cancer patients: an update. Ann Oncol. 2012;23 Suppl 10: x302-5.

64 Reich M, Lesur A, Perdrizet-Chevallier C. Depression, quality of life and breast cancer: a review of the literature. Breast Cancer Res Treat. 2008;110:9-17.

65 Lin PH, Liu JM, Hsu RJ, Chuang HC, Chang SW, Pang ST, et al. Depression negatively impacts survival of patients with metastatic prostate cancer. Int J Environ Res Public Health. 2018;15:2148.

66 Chan CM, Ahmad WA, Yusof MM, Ho GF, Krupat E. Effects of depression and anxiety on mortality in a mixed cancer group: a longitudinal approach using standardised diagnostic interviews. Psychooncology. 2015;24:718-25.

67 Ariyo AA, Haan M, Tangen CM, Rutledge JC, Cushman M, Dobs A, et al. Depressive symptoms and risks of coronary heart disease and mortality in elderly Americans. cardiovascular health study collaborative research group. Circulation. 2000;102:1773-9.

68 Egede LE, Nietert PJ, Zheng D. Depression and all-cause and coronary heart disease mortality among adults with and without diabetes. Diabetes Care. 2005;28:1339-45.

69 Hazuda HP, Gaussoin SA, Wing RR, Yanovski SZ, Johnson KC, Coday $\mathrm{M}$, et al. Long-term association of depression symptoms and antidepressant medication use with incident cardiovascular events in the look AHEAD (Action for Health in Diabetes) clinical trial of weight loss in type 2 diabetes. Diabetes Care. 2019;42:910-8.

70 Lett HS, Blumenthal JA, Babyak MA, Sherwood A, Strauman T, Robins $C$, et al. Depression as a risk factor for coronary artery disease: evidence, mechanisms, and treatment. Psychosom Med. 2004;66:305-15.

71 Bos MJ, Lindén T, Koudstaal PJ, Hofman A, Skoog I, Breteler MM, et al. Depressive symptoms and risk of stroke: the Rotterdam study. J Neurol Neurosurg Psychiatry. 2008;79:997-1001.

72 Li CT, Bai YM, Tu PC, Lee YC, Huang YL, Chen TJ, et al. Major depressive disorder and stroke risks: A 9-year follow-up populationbased, matched cohort study. PLoS One. 2012;7:e46818.

73 Péquignot R, Dufouil C, Prugger C, Pérès K, Artero S, Tzourio C, et al. High level of depressive symptoms at repeated study visits and risk of coronary heart disease and stroke over 10 years in older adults: the three-city study. J Am Geriatr Soc. 2016;64:118-25.

74 Zhao $F$, Yue $Y$, Jiang $H$, Yuan $Y$. Shared genetic risk factors for depression and stroke. Prog Neuropsychopharmacol Biol Psychiatry. 2019;93:55-70.

75 Gustad LT, Laugsand LE, Janszky I, Dalen H, Bjerkeset O. Symptoms of anxiety and depression and risk of heart failure: the HUNT study. Eur J Heart Fail. 2014;16:861-70. 